\title{
A small-molecule compound targeting CCR5 and CXCR3 prevents airway hyperresponsiveness and inflammation
}

\author{
Y. Suzaki*, K. Hamada*, T. Nomi ${ }^{\#}$, T. Ito*, M. Sho* , Y. Kai*, \\ Y. Nakajima\# ${ }^{\#}$ and H. Kimura*
}

ABSTRACT: Asthma is associated with increased numbers of T-cells in the lung. CC chemokine receptor (CCR)5 and CXC chemokine receptor (CXCR)3 have been reported to play important roles in the lung T-cell homing pathway, and may be potential targets for asthma therapy. The aim of the present study was to investigate the role of CCR5 and CXCR3 in allergen-induced acute asthma and to determine whether a novel small-molecule compound, TAK-779, targeting CCR5 and CXCR3 can attenuate allergic airway responses.

Mice were sensitised with ovalbumin (OVA). mRNA expression of chemokine receptors in the lung were measured after the challenge with either aerosolised phosphate-buffered saline or OVA. OVA-sensitised mice were also treated with TAK-779. Respiratory function was measured, bronchoalveolar lavage was performed, and blood and lung samples were obtained.

OVA challenge increased CCR3, CCR5 and CXCR3 expression in the lung. Treatment with TAK779 significantly attenuated altered respiratory function and pulmonary allergic inflammation. The beneficial effect was associated with reduced expression of CCR5 and CXCR3 in the lung.

These data demonstrate that blockade of CC chemokine receptor 5 and CXC chemokine receptor 3 using TAK-779, a synthetic nonpeptide compound, can prevent the development of asthma features in a mouse model. Thus, CC chemokine receptor 5 and $\mathrm{CXC}$ chemokine receptor 3 may be potential targets for asthma therapy.

KEYWORDS: Asthma, CC chemokine receptor 5, chemokine, CXC chemokine receptor 3, cytokine

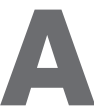

sthma is characterised by a large influx of CD4+ T-cells and eosinophils in the bronchial lamina propria $[1,2]$. The fact that lung eosinophilia and bronchial hyperreactivity do not occur in the absence of T-cells supports a critical role of T-cells in asthma $[3,4]$. Thus, preventing the recruitment of T-cells to sites of airway inflammation may be an attractive therapeutic strategy for asthma. Lymphocyte recruitment is controlled by adhesion molecules and chemoattractant signals expressed by high endothelial venules and post-capillary venular endothelium. Chemokines are chemotactic cytokines that regulate not only the migration of leukocytes but also their activation and differentiation by binding to specific cell surface receptors on target cells $[5,6]$. Chemokines play important roles in a variety of inflammatory disease conditions, such as asthma, inflammatory bowel disease, and infectious diseases [5]. In the field of asthma, several chemokines and chemokine receptors, such as eotaxin, RANTES (regulated on activation normal T-cell expressed and secreted), macrophage inflammatory protein (MIP)- $1 \alpha$, monocyte chemoattractant protein (MCP)-1, MCP-5, and CC chemokine receptors CCR1, CCR3 and CCR5, have been suggested to be critical in the development of allergic airway inflammatory response in animal models [3, 7-9]. Furthermore, CCR5 and CXC chemokine receptor (CXCR)3 have been reported to be expressed on human lung T-cells [10]. These observations indicate that CCR5 and CXCR3 have important roles in homing T-cells to the lung.

The objective of the present study was to test the hypothesis that blockade of CCR5 and CXCR3 could prevent the development of asthma mainly by inhibiting the recruitment of T-cells to the lung. To this end, TAK-779, a novel CCR5 and CXCR3 antagonist, was used. TAK-779 has been developed as an anti-HIV-1 agent, since CCR5 acts as a major co-receptor for fusion and entry of macrophage-tropic HIV-1 into the host cells [11, 12]. TAK-779 is a synthetic small-molecule nonpeptide compound that inhibits the ligands,
AFFILIATIONS

*Second Dept of Internal Medicine, and \#Dept of Surgery, Nara Medical University, Nara, Japan.

CORRESPONDENCE

K. Hamada

Second Dept of Internal Medicine Nara Medical University

840 Shijo-cho

Kashihara Nara 634-8522

Japan

Fax: 81744290907

E-mail: khamada@naramed-u.ac.jp

Received:

August 252007

Accepted after revision:

November 292007

\section{SUPPORT STATEMENT}

This study was supported, in part, by a grant from the Respiratory Failure Research Group for the Ministry of Health, Labor and Welfare, Japan.

STATEMENT OF INTEREST

None declared. 
RANTES, MIP-1a or MIP-1b, from binding to CCR5 and blocks chemokine-induced chemotaxis in vitro [11, 13]. CCR5 is expressed on activated T-helper cells (Th) type 1, macrophages, dendritic cells and natural killer (NK) cells [5]. Furthermore, it has been recently demonstrated that TAK-779 also has the ability to block the binding of CXCR3 and inhibitory protein (IP)-10, one of the CXCR3 ligands, and also inhibits cell adhesion or chemotaxis induced by its ligands in vitro [13]. CXCR3 is exclusively expressed on activated Th1 cells, NK cells and B-cells [5, 14, 15]. Therefore, TAK-779 has the ability to control physiological and pathological responses that are mediated by both CCR5 and CXCR3. Recently, AKASHI et al. [16] reported that TAK-779 treatment inhibited the recruitment of alloreactive cells into the grafts, which resulted in the prolongation of graft survival using transplant mouse models in which CCR5 and CXCR3 have important roles. The present data indicate that CCR5 and CXCR3 have important roles in the development of allergen-induced asthma. The significant effect of TAK-779 on prevention of physiological and pathological features of asthma in a mouse model supports future targeting of CCR5 and CXCR3 in humans.

\section{MATERIALS AND METHODS}

\section{Animals}

Female BALB/c mice at 8 weeks old were purchased from Japan SLC (Shizuoka, Japan). The mice were housed in the animal facility of Nara Medical University (Kashihara Nara, Japan), which was maintained at $22-24^{\circ} \mathrm{C}$ with a 12 -h dark/ light cycle, fed a commercial pelleted mouse food and given water ad libitum under specific pathogen-free conditions according to standard guidelines for the care and use of laboratory animals [17]. All experiments were conducted under protocols approved by the Nara Medical University Review Board, Nara, Japan.

\section{Allergen sensitisation and exposure}

The mice were sensitised by initial intraperitoneal injection of $0.4 \mathrm{~mL}$ phosphate-buffered saline (PBS) containing ovalbumin (OVA; $20 \mu \mathrm{g}$, grade 3; Sigma-Aldrich, St Louis, MO, USA) and alum (2 mg). After 1 week, the mice were further sensitised with the same reagent. On day 10 after the second sensitisation (day 18), the mice were exposed to aerosols of allergen $(1 \%$ (weight/volume) OVA in PBS, $\mathrm{pH} 7.4$ ) for $10 \mathrm{~min}$ on 3 consecutive days (days 18-20). The aerosol exposure was performed in a chamber using a PARI nebuliser (PARI Japan, Osaka, Japan). In the control group, the mice were sensitised with OVA and exposed to aerosols of PBS.

\section{Administration of TAK-779}

A small-molecule nonpeptide compound, TAK-779 (N,Ndimethyl- $\mathrm{N}$-[4-[[[2-(4-methylphenyl)-6,7-dihydro-5H-benzocyclohepten-8-yl]carbonyl]amino]benzyl]tetra-hydro-2H-pyran-4aminium chloride; molecular weight $=531.13 \mathrm{~g} \cdot \mathrm{mol}^{-1}$ ) was provided by Takeda Chemical Industries Ltd (Osaka, Japan). The chemical structure has been described previously [11]. It was diluted with sterile water to make a final concentration of $0.5 \mathrm{mg} \cdot \mathrm{mL}^{-1}$. TAK-779 $\left(250 \mathrm{mg} \cdot \mathrm{day}^{-1}\right)$ was subcutaneously administrated on 3 consecutive days from day 18 to day 20. Mice administered with TAK-779 appeared healthy, showed regular weight gain and activity levels similar to control mice, and had no ulceration at the injection sites.

\section{Pulmonary function testing}

The responsiveness of mice to increasing concentrations of aerosolised methacholine was measured $24 \mathrm{~h}$ after the last challenge using whole body plethysmography (Buxco, Wilmington, NC, USA), as previously described [18, 19]. The main indicator of airflow obstruction, enhanced pause (Penh), which shows strong correlation with the airway resistance examined by standard evaluation methods (see Discussion), was calculated from the box waveform [20]. Aerosolised saline or methacholine was nebulised in increasing concentrations (6, $12,25,50 \mathrm{mg} \cdot \mathrm{mL}^{-1}$ ) for $1 \mathrm{~min}$, and Penh measurements were taken for $5 \mathrm{~min}$ after each dose. Penh values for the $5 \mathrm{~min}$ were averaged and used to compare results across treatment groups and individual mice.

\section{Pathological analysis}

The animals were euthanised with sodium pentobarbital (Nakalai Tesque Inc., Kyoto, Japan) $24 \mathrm{~h}$ after physiological testing. Serum was collected and stored at $-20^{\circ} \mathrm{C}$. Bronchoalveolar lavage (BAL) was performed, and BAL fluid (BALF) cells and differentials were counted as previously described [18, 19]. After BAL, some of the lungs were instilled with $10 \%$ buffered formalin, removed and fixed in the same solution. After paraffin embedding, sections for microscopy were stained with haematoxylin and eosin (H\&E). An index of pathological changes in coded H\&E slides was delivered by scoring the inflammatory cell infiltrates around airways and vessels for greatest severity (0: normal; 1 : $<3$ cell diameter thick; 2 : 4-10 cells thick; 3 : $>10$ cells thick) and overall extent (0: normal; $1:<25 \%$ of sample; $2: 25$ $75 \% ; 3:>75 \%)$. The index was calculated by multiplying severity by extent, with a maximum possible score of 9 . Metaplastic goblet cells were identified by the abundant cytoplasm filled with mucin and by the flattened nuclei.

\section{Assay of serum immunoglobulin E}

Anti-OVA-specific immunoglobulin (Ig)E antibody was measured by ELISA as previously described [21]. For a positive control standard, a monoclonal anti-OVA IgE was used (2C6; Serotec, Kidlington, UK) [18].

\section{Extraction of total RNAs and quantitative real-time PCR analysis}

Total RNA was isolated from whole lung by using guanidine isothiocyanate methods $48 \mathrm{~h}$ after the last challenge and was transcribed to cDNA using Omniscript Reverse Transcriptase (QIAGEN, Hilden, Germany) and amplified with oligo dT primers (Amersham Biosciences Corp., Piscataway, NJ, USA). Quantitative real-time PCR analysis was performed using the ABI Prism 7700 sequence detector system (PE Applied Biosystems, Foster City, CA, USA). Primer/probe sets were purchased from PE Applied Biosystems. PCR was carried out with the TaqMan Universal PCR Master Mix (PE Applied Biosystems) using $1 \mu \mathrm{L}$ of cDNA in a $20-\mu \mathrm{L}$ final reaction volume. The PCR thermal cycle conditions were as follows: initial step at $95^{\circ} \mathrm{C}$ for $10 \mathrm{~min}$, followed by 40 cycles of $95^{\circ} \mathrm{C}$ for $15 \mathrm{~s}$ and $60^{\circ} \mathrm{C}$ for $1 \mathrm{~min}$. The expression levels of each mRNA were divided by levels of mRNA of the housekeeping gene $\beta_{2^{-}}$ microglobulin. 


\section{Statistical analysis}

Data are presented as mean \pm SEM. ANOVA analysis of differences among group means was performed using Fisher's protected least significant difference test. A p-value $<0.05$ was considered statistically significant.

\section{RESULTS}

\section{Increased CCR3, CCR5 and CXCR3 expression in the} airways after allergen challenge

First, several potent chemokine receptors, including CCR5 and CCR3, were examined in the model. Quantitative real-time PCR analysis showed the increased mRNA expression of CCR3, CCR5 and CXCR3 in the lung of OVA-sensitised and -exposed mice compared with OVA-sensitised and PBSexposed mice (fig. 1).

\section{Effects of TAK-779 treatment}

Following this, the protective effect of TAK-779 administration on key features of the present mouse model of asthma was evaluated. OVA-sensitised and -exposed mice showed increased total cells, lymphocytes and eosinophils on BALF compared with control mice sensitised with OVA and exposed to PBS (fig. 2a). TAK-779 treatment significantly decreased the number of total cells, lymphocytes and eosinophils on BALF (fig. 2a). Results of semiquantitative scoring of histological changes further support the qualitative changes presented in figure $2 \mathrm{~b}$. While control mice showed robust pathological changes in allergic pulmonary inflammation (AI; eosinophil and mononuclear cell infiltration around airways and vessels and goblet cell hyperplasia), TAK-779 treatment significantly diminished the pathological changes in AI (fig. 2c and d). Altered respiratory function was assessed as an increased Penh in response to increasing doses of methacholine. OVA-sensitised and -exposed mice showed altered respiratory function (fig. 3), which manifested as increased Penh values compared with those seen in control mice sensitised with OVA and challenged with aerosols of PBS. In contrast, OVA-sensitised and -exposed mice treated with TAK-779 showed minimal changes in respiratory function, and were comparable with the control group (fig. 3). Serum OVA-specific IgE was increased in
OVA-sensitised and -exposed mice. TAK-779 treatment did not reduce serum OVA-specific IgE production (fig. 4).

\section{TAK-779 downregulates the expression of chemokine receptors and Th1 cytokines}

To further characterise the underlying mechanisms responsible for the marked decrease in allergic response in lungs of TAK779-treated mice, the local expression of chemokines, chemokine receptors and cytokines was analysed by quantitative real-time PCR. TAK-779 treatment significantly downregulated the expression of CCR5 and CXCR3, which was upregulated in OVA-sensitised and -exposed mice compared with mice sensitised with OVA and exposed to aerosols of PBS (fig. 5). In contrast, the expression of CCR3, which was also upregulated in OVA-sensitised and -exposed mice, was not downregulated by TAK-779 treatment (fig. 5). Moreover, the expression of both Th1 (interferon (IFN)- $\gamma$ and tumour necrosis factor (TNF)- $\alpha$ ) and Th2 (interleukin (IL)-4 and IL-13) cytokines were higher in OVA-sensitised and -exposed mice compared with mice sensitised with OVA and exposed to aerosols of PBS (fig. 6). Th1 cytokines (IFN- $\gamma$ and TNF- $\alpha$ ) were significantly downregulated by TAK-779 treatment (fig. 6). In contrast, the expressions of Th2 cytokines (IL-4 and IL-13) were not downregulated by TAK-779 treatment (fig. 6). However, the ligands for CCR5 and CXCR3, RANTES, MIP-1a, IP-10 and monokine induced by IFN- $\gamma$ were not upregulated in the present asthma model (data not shown).

\section{DISCUSSION}

The incidence and prevalence of asthma have markedly risen in industrialised countries [22]. Although some success has been seen with the use of anti-inflammatory drugs, many therapeutic challenges remain, including chronic airway remodelling changes and steroid-resistant severe asthma. To overcome these problems, novel targets and approaches are needed to suppress AI and airway hyperresponsiveness (AHR), two defining characteristics of asthma. Most current therapies are designed to suppress the inflammation that is mainly caused by inflammatory cells already recruited to the airways. In contrast, inhibiting the initial recruitment of T-cells
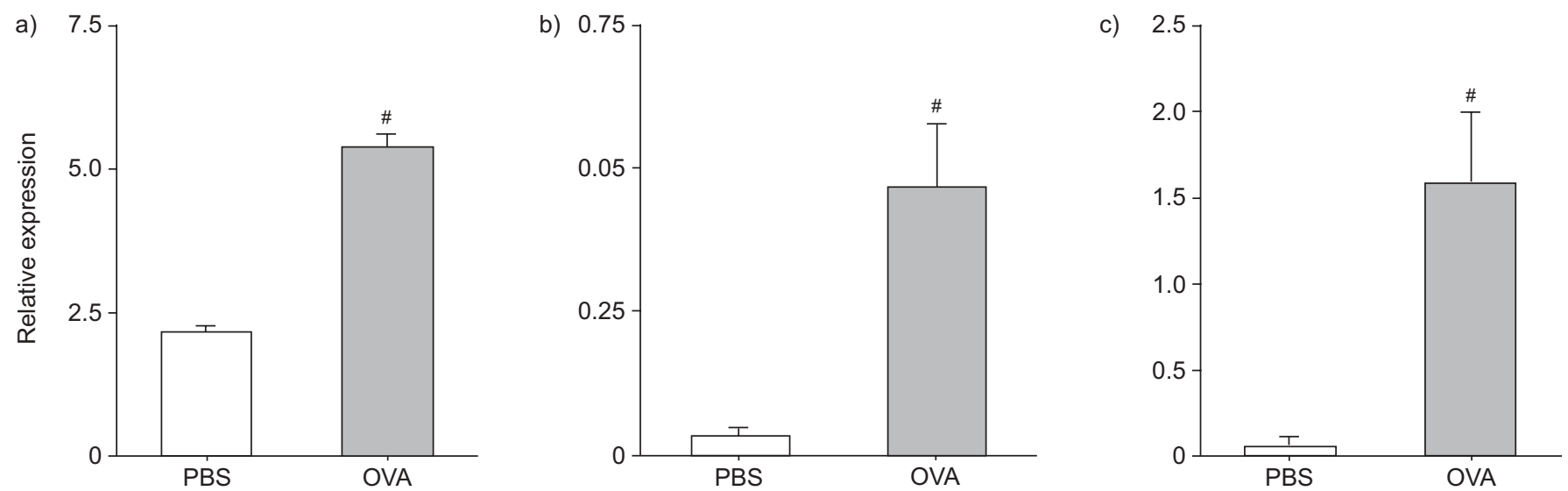

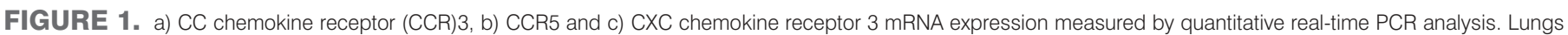

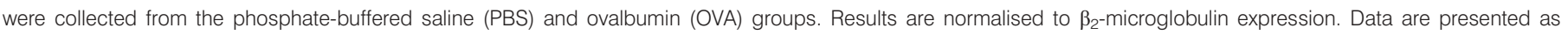
mean \pm SEM and were obtained from three to five mice in each group. ${ }^{*}: p<0.0005$ 

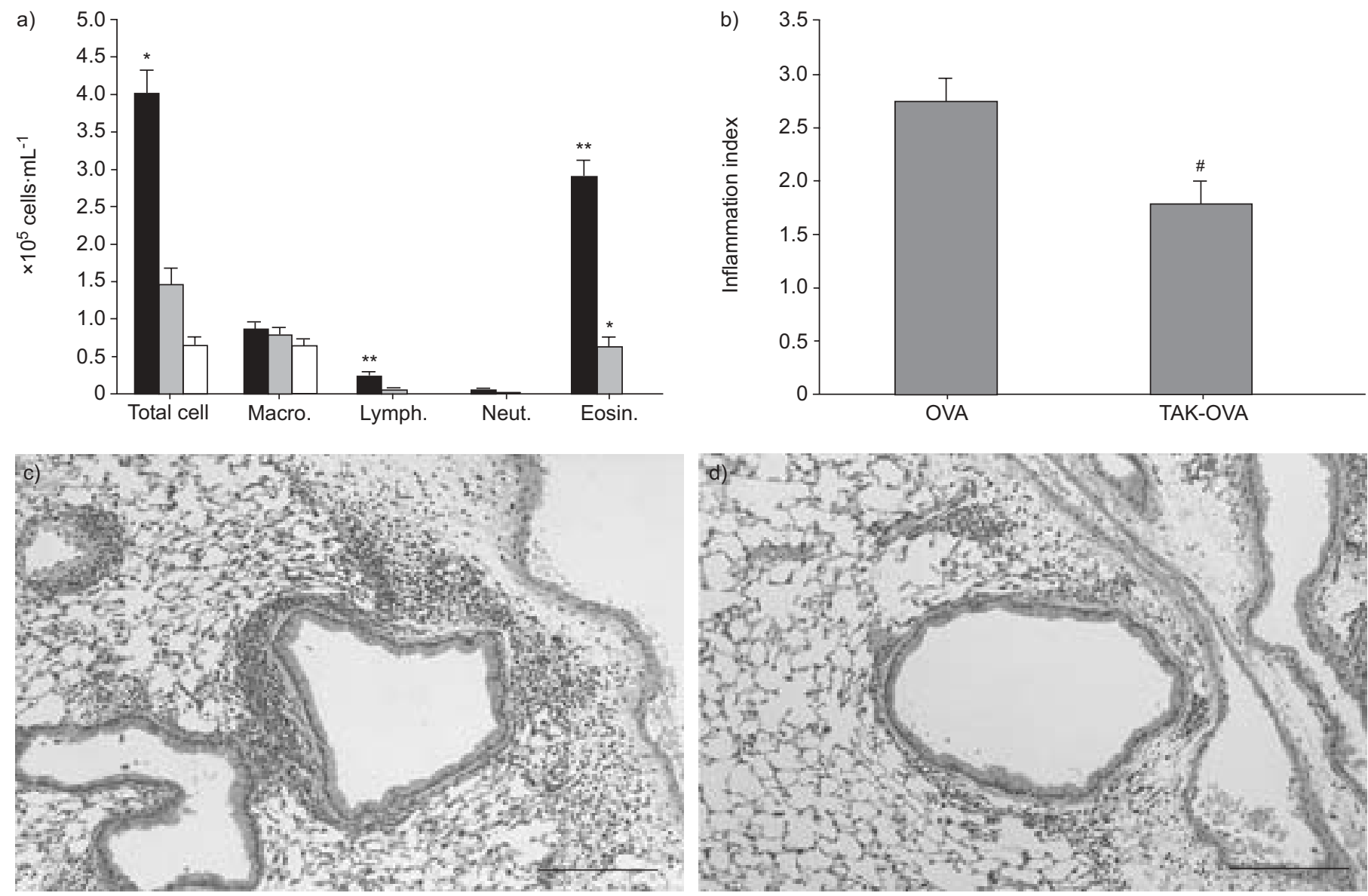

FIGURE 2. Effect of TAK-779 on allergic pulmonary inflammation. a) Bronchoalveolar lavage cell findings ( $\mathrm{n}=10$ for each group).

: ovalbumin (OVA); 1 : TAK+OVA; $\square$ : phosphate-buffered saline (PBS). b) Semiquantative analysis of histopathological changes ( $n=5$ per group). Representative lung histology findings from c) the OVA and d) OVA with TAK-779 treatment groups. Macro.: macrophage; Lymph.: Iymphocyte; Neut.: neutrophil; Eosin.: eosinophil. *: p<0.05 versus PBS group; **: p<0.01 versus other groups; $\#$ : $p<0.005$. Scale bars $=200 \mu \mathrm{m}$

to the airways represents a novel approach, especially since these cells play a central role in the development of asthma.

The present study examined whether blockade of CCR5 and CXCR3 had a beneficial effect on the development of asthma features. The context for the present study includes data suggesting that CCR5 and CXCR3 may have an important role in the homing of T-cells to the lung. CAMPBELL et al. [23] reported that human lung T-cells expressed CCR5 and CXCR3, and only low levels of CCR 4 and $\alpha_{4} \beta_{7}$. This profile is distinct from that of gut- and skin-homing T-cells, although both CCR5 and CXCR3 are not specific for the lung [23-26]. These data implied that CCR5 and CXCR3 could be a potent therapeutic target of asthma for inhibiting the recruitment of T-cells to the airways.

There were two major findings in the present study. First, it was found that the expression of the Th1-linked chemokine receptors (CR), CCR5 and CXCR3, were significantly upregulated in the lungs of OVA-sensitised and -exposed mice. The expression of the Th2-linked CR, the major CR expressed on eosinophils, CCR3 was also upregulated in the present model. Th1 cells appear to preferentially express CCR5 and CXCR3, whereas Th2 cells preferentially express CCR4 and, to a lesser extent, CCR3 [27]. The chemokine system in vivo is extremely redundant due to the large number of different chemokines, the overlap in chemokine function and the pleiotrophy of chemokine-receptor interaction. One of the challenges in this field is to identify which receptors play major roles in specific inflammatory conditions. The current findings suggest that the Th2-linked CRs are not the only potential targets for asthma therapy. The Th1-linked CRs, especially CCR5 and CXCR3 may also be valid targets [28].

Indeed, the second major finding of the study was that TAK779, which has the ability to antagonise CCR5 and CXCR3, significantly prevented the pathophysiological features of asthma. This was demonstrated by attenuation of altered respiratory function and decreased AI. Furthermore, TAK-779 treatment significantly downregulated the expression of CCR5 and CXCR3 in the lung of OVA-induced asthma mice. To date, it is not possible to satisfactorily explain which immune cells inhibited the recruitment into lungs by TAK-779. However, the hypothesis that TAK-779 has an inhibitory effect on the recruitment of immune cells, including Th1 cells, into the lungs comes from the observation of downregulated expression of CCR5 and CXCR3 expressed on Th1 cells, and Th1 cytokines (IFN- $\gamma$ and TNF- $\alpha$ ) in the lungs by TAK-779 treatment. It has now become increasingly clear that Th1 cells have a 


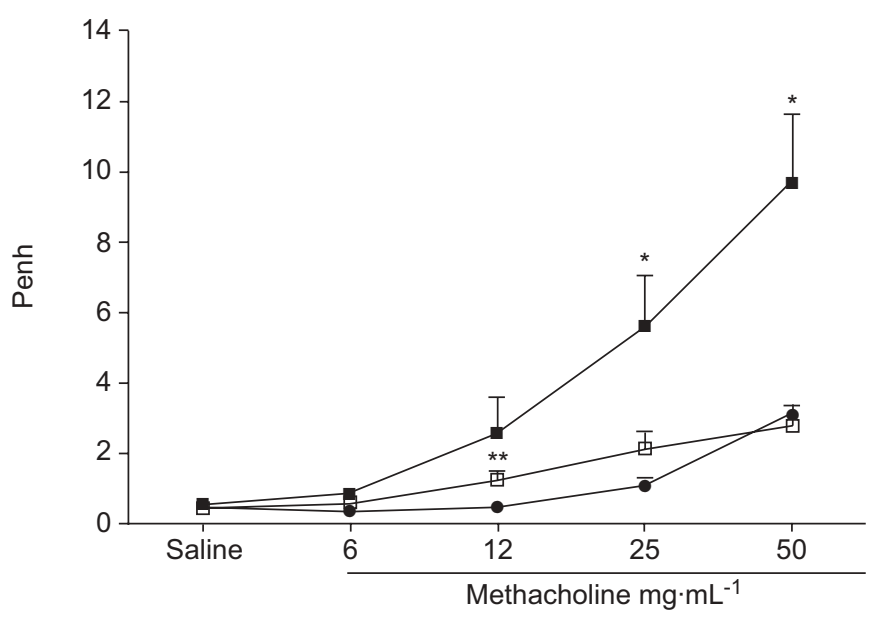

FIGURE 3. Effect of TAK-779 on respiratory function to inhaled methacholine, measured by whole body plethysmography. Penh: enhanced pause. $\mathbf{\square}$ : ovalbumin (OVA); $\square$ : TAK-OVA; $\bullet$ : phosphate-buffered saline (PBS). For each group $n=5$. *: $p<0.05$ versus other groups; **: $p<0.01$ versus PBS group.

pro-inflammatory role in the Th2-governed disorder, asthma [29-31]. Furthermore, some data has demonstrated that IFN- $\gamma$ contributes to the development of AHR and AI in experimental asthma [32, 33]. Thus, the beneficial effect of TAK-779 on asthma development may depend, at least in part, on preventing the infiltration of Th1 cells into the lung. However, the present authors speculate that the prevention of infiltration of other immune cells might contribute to the dramatic inhibition of physiological (altered respiratory function) and pathological (BAL and histopathology) measures of asthma severity in the current model.

Some limitations of the study merit discussion. Noninvasive plethysmography was used to measure Penh as an index of altered respiratory function, a technique that has been the subject of considerable controversy [34]. However, the best, and arguably most useful, correlation of Penh with more invasive measures of airway function is found in BALB/c mice

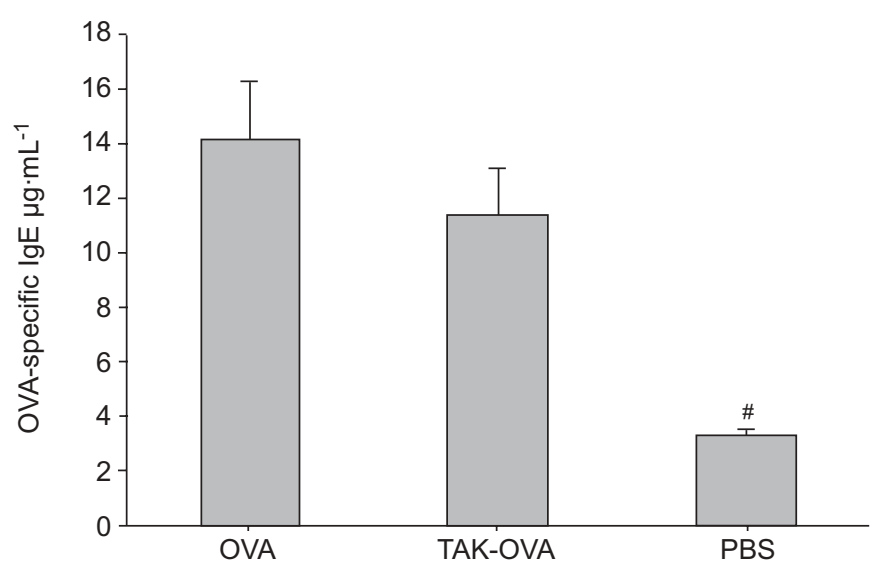

FIGURE 4. Effect of TAK-779 on the production of serum ovalbumin (OVA)specific immunoglobulin (Ig)E. PBS: phosphate-buffered saline. For each group $n=5 .{ }^{*}: p<0.0001$ versus other groups.

after OVA-sensitisation and aerosol challenge protocols, as used in other studies. Indeed, ADLER et al. [35] reported that Penh correlates well with lung resistance in the OVA-allergy model in BALB/c mouse. Since direct testing of AHR was not performed, the changes in Penh were described as altered respiratory function. The semiquantitative analysis of tissue inflammation has limitations since it is not a rigorous morphometric technique. Nevertheless, it complements (and is consistent with) the more quantitative analysis of AI by BAL. Moreover, the combined analyses of airway function and inflammation responses are internally consistent.

CHVATCHко et al. [9] reported that the blockage of CCR5 using amino-terminally modified RANTES/CC chemokine ligand 5 analogues led to decreased AI, but did not affect AHR in a mouse model of OVA-induced asthma. In contrast, in the current study, the blockage of CCR5 using TAK-779 significantly inhibited altered respiratory function as well as AI. The basis for this is not clear but may reflect the use of a new synthetic small-molecule nonpeptide compound to block CCR5. Amino-terminally modified RANTES/CC chemokine
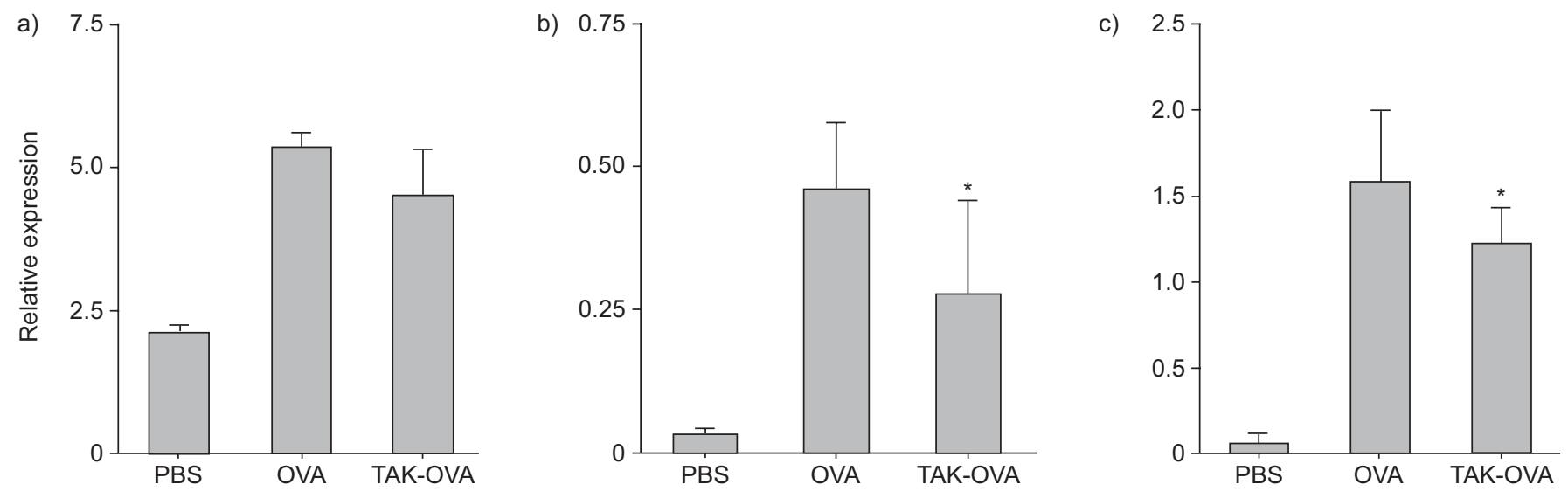

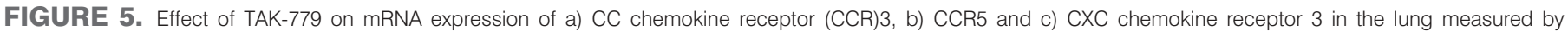

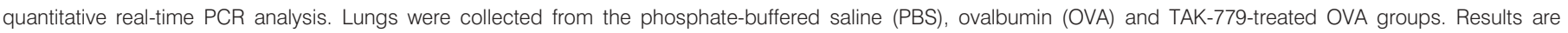
normalised to $\beta_{2}$-microglobulin expression. Data are presented as mean \pm SEM and were obtained from three to five mice in each group. ${ }^{*}$ : $<<0.05$ versus $O V A$ group. 

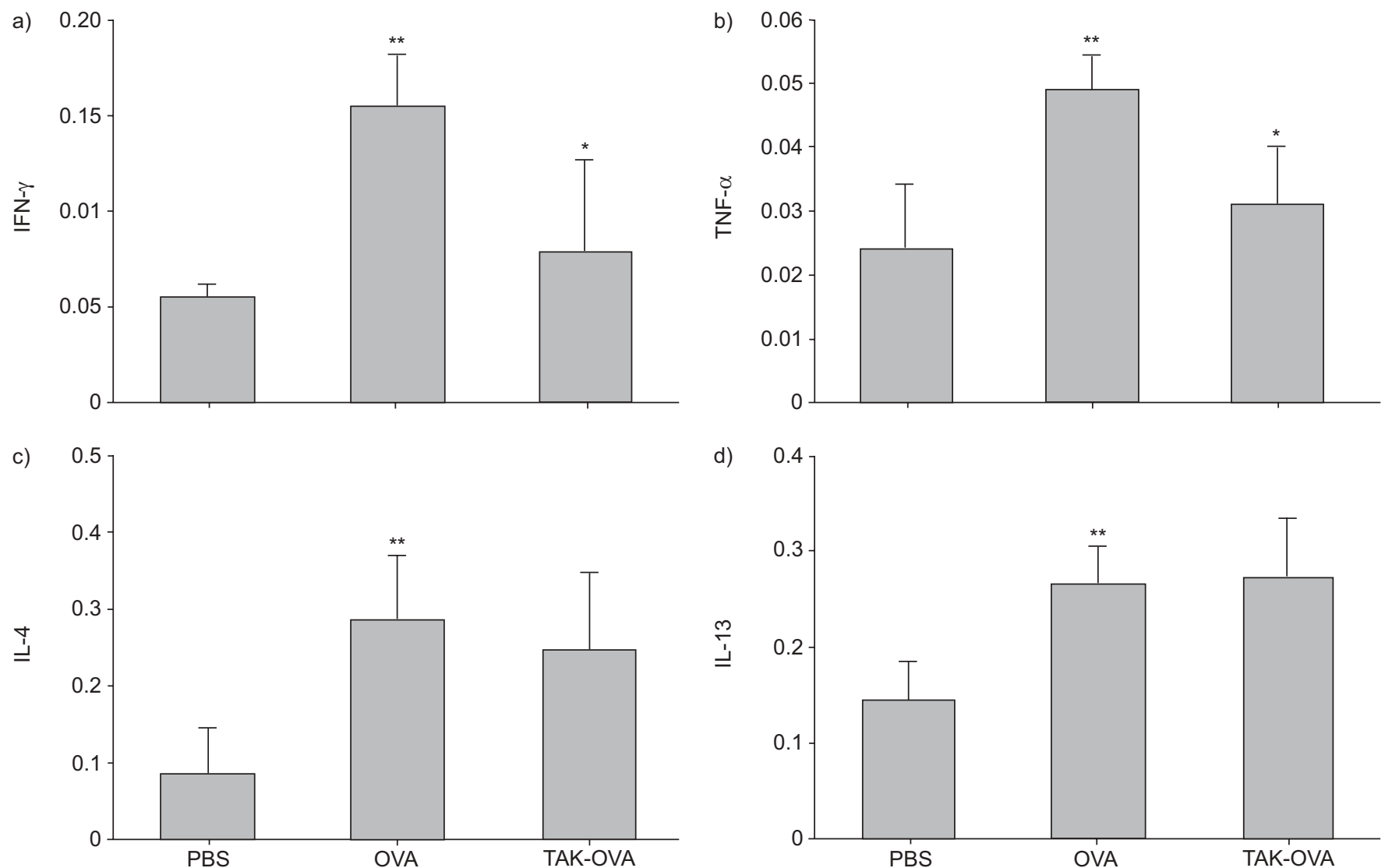

FIGURE 6. Effect of TAK-779 on mRNA expression of a) interferon (IFN)- $\gamma$, b) tumour necrosis factor (TNF)- $\alpha$, c) interleukin (IL)-4 and d) IL-13 in the lung measured by quantitative real-time PCR analysis. Lungs were collected from phosphate buffered saline (PBS), ovalbumin (OVA) and TAK-779-treated OVA group. Results are normalised to $\beta_{2}$-microglobulin expression. Data are presented as mean \pm SEM and were obtained from three to five mice in each group. *: $p<0.05$ versus OVA group; **: $p<0.01$ versus PBS groups.

ligand 5 analogues have the ability to antagonise both CCR1 and CCR5. Conversely, TAK-779 has been reported to have the ability to antagonise both CCR5 and CXCR3, and to control a physiological and pathological response that is mediated by both CCR5 and CXCR3 [13]. Therefore, the blockage of both CCR5 and CXCR3 may be more effective in preventing the development of asthma responses as opposed to only targeting CCR5, or CCR5 and CCR1. Further studies are needed to address this question by using mice deficient for either receptor, and by using neutralising monoclonal antibodies or specific receptor small-molecule antagonists.

In conclusion, the present authors demonstrated for the first time that the blockade of CC chemokine receptor 5 and $\mathrm{CXC}$ chemokine receptor 3 by the administration of a novel, smallmolecule compound, TAK-779, can prevent the development of key features of asthma in a mouse model (both altered respiratory function and airway inflammation). The present data indicate that targeting $\mathrm{CC}$ chemokine receptor 5 and $\mathrm{CXC}$ chemokine receptor 3 may have a therapeutic potential in clinical asthma. Thus, future studies of the therapeutic potential of TAK-779, other small-molecule chemokine receptors, antagonists and blocking antibodies targeting CC chemokine receptor 5 and $\mathrm{CXC}$ chemokine receptor 3 for both acute and chronic aspects of asthma are warranted.

\section{ACKNOWLEDGEMENTS}

The authors would like to thank L. Kobzik (Dept of Environmental Health, Harvard School of Public Health, Boston, MA, USA) for helpful and valuable comments on the manuscript and also K. Kubo and the animal facility staff at Nara Medical University (Kashihara Nara, Japan) for their excellent animal care and support of the research.

\section{REFERENCES}

1 Azzawi M, Bradley B, Jeffery PK, et al. Identification of activated $\mathrm{T}$ lymphocytes and eosinophils in bronchial biopsies in stable atopic asthma. Am Rev Respir Dis 1990; 142: 1407-1413.

2 Anderson GP, Coyle AJ. TH2 and "TH2-like" cells in allergy and asthma: pharmacological perspectives. Trends Pharmacol Sci 1994; 15: 324-332.

3 Gonzalo JA, Lloyd CM, Wen D, et al. The coordinated action of CC chemokines in the lung orchestrates allergic inflammation and airway hyperresponsiveness. J Exp Med 1998; 188: 157-167.

4 Gavett SH, Chen X, Finkelman F, Wills-Karp M. Depletion of murine CD4+ T lymphocytes prevents antigen-induced airway hyperreactivity and pulmonary eosinophilia. Am J Respir Cell Mol Biol 1994; 10: 587-593. 
5 Luster AD. Chemokines-chemotactic cytokines that mediate inflammation. $N$ Engl J Med 1998; 338: 436-445.

6 Luther SA, Cyster JG. Chemokines as regulators of T cell differentiation. Nat Immunol 2001; 2: 102-107.

7 Jia GQ, Gonzalo JA, Lloyd C, et al. Distinct expression and function of the novel mouse chemokine monocyte chemotactic protein-5 in lung allergic inflammation. J Exp Med 1996; 184: 1939-1951.

8 MacLean JA, Ownbey R, Luster AD. T cell-dependent regulation of eotaxin in antigen-induced pulmonary eosinophila. J Exp Med 1996; 184: 1461-1469.

9 Chvatchko Y, Proudfoot AE, Buser R, et al. Inhibition of airway inflammation by amino-terminally modified RANTES/CC chemokine ligand 5 analogues is not mediated through CCR3. J Immunol 2003; 171: 5498-5506.

10 Campbell JJ, Brightling CE, Symon FA, et al. Expression of chemokine receptors by lung $\mathrm{T}$ cells from normal and asthmatic subjects. J Immunol 2001; 166: 2842-2848.

11 Baba M, Nishimura O, Kanzaki N, et al. A small-molecule, nonpeptide CCR5 antagonist with highly potent and selective anti-HIV-1 activity. Proc Natl Acad Sci USA 1999; 96: 5698-5703.

12 Alkhatib G, Combadiere C, Broder CC, et al. CC CKR5: a RANTES, MIP-1 $\alpha$, MIP- $1 \beta$ receptor as a fusion cofactor for macrophage-tropic HIV-1. Science 1996; 272: 1955-1958.

13 Gao P, Zhou XY, Yashiro-Ohtani Y, et al. The unique target specificity of a nonpeptide chemokine receptor antagonist: selective blockade of two Th1 chemokine receptors CCR5 and CXCR3. J Leukoc Biol 2003; 73: 273-280.

14 Hancock WW. Chemokine receptor-dependent alloresponses. Immunol Rev 2003; 196: 37-50.

15 Qin S, Rottman JB, Myers P, et al. The chemokine receptors CXCR3 and CCR5 mark subsets of T cells associated with certain inflammatory reactions. J Clin Invest 1998; 101: 746-754.

16 Akashi S, Sho M, Kashizuka $\mathrm{H}$, et al. A novel smallmolecule compound targeting CCR5 and CXCR3 prevents acute and chronic allograft rejection. Transplantation 2005; 80: 378-384.

17 National Research Council, Institute of Laboratory Animal Research, Commission on Life Science. Guide for the Care and Use of Laboratory Animals. Washington DC, National Academy Press, 1996.

18 Hamada K, Suzaki Y, Goldman A, et al. Allergenindependent maternal transmission of asthma susceptibility. J Immunol 2003; 170: 1683-1689.

19 Suzaki Y, Hamada K, Sho M, et al. A potent antiangiogenic factor, endostatin prevents the development of asthma in a murine model. J Allergy Clin Immunol 2005; 116: 1220-1227.

20 Hamelmann E, Schwarze J, Takeda K, et al. Noninvasive measurement of airway responsiveness in allergic mice using barometric plethysmography. Am J Respir Crit Care Med 1997; 156: 766-775.

21 Hamada K, Goldsmith CA, Kobzik L. Increased airway hyperresponsiveness and inflammation in a juvenile mouse model of asthma exposed to air-pollutant aerosol. J Toxicol Environ Health A 1999; 58: 129-143.

22 Hartert TV, Peebles RS Jr. Epidemiology of asthma: the year in review. Curr Opin Pulm Med 2000; 6: 4-9.

23 Campbell JJ, Haraldsen G, Pan J, et al. The chemokine receptor CCR4 in vascular recognition by cutaneous but not intestinal memory T cells. Nature 1999; 400: 776-780.

24 Bargatze RF, Jutila MA, Butcher EC. Distinct roles of Lselectin and integrins $\alpha 4 \beta 7$ and LFA- 1 in lymphocyte homing to Peyer's patch-HEV in situ: the multistep model confirmed and refined. Immunity 1995; 3: 99-108.

25 Kunkel EJ, Campbell JJ, Haraldsen G, et al. Lymphocyte CC chemokine receptor 9 and epithelial thymus-expressed chemokine (TECK) expression distinguish the small intestinal immune compartment: epithelial expression of tissue-specific chemokines as an organizing principle in regional immunity. J Exp Med 2000; 192: 761-768.

26 Zabel BA, Agace WW, Campbell JJ, et al. Human G protein-coupled receptor GPR-9-6/CC chemokine receptor 9 is selectively expressed on intestinal homing $\mathrm{T}$ lymphocytes, mucosal lymphocytes, and thymocytes and is required for thymus-expressed chemokine-mediated chemotaxis. J Exp Med 1999; 190: 1241-1256.

27 Bonecchi R, Bianchi G, Bordignon PP, et al. Differential expression of chemokine receptors and chemotactic responsiveness of type $1 \mathrm{~T}$ helper cells (Th1s) and Th2s. J Exp Med 1998; 187: 129-134.

28 Randolph DA, Stephens R, Carruthers CJ, Chaplin DD. Cooperation between Th1 and Th2 cells in a murine model of eosinophilic airway inflammation. J Clin Invest 1999; 104: 1021-1029.

29 Hansen G, Berry G, DeKruyff RH, Umetsu DT. Allergenspecific Th1 cells fail to counterbalance Th2 cell-induced airway hyperreactivity but cause severe airway inflammation. J Clin Invest 1999; 103: 175-183.

30 Randolph DA, Carruthers CJ, Szabo SJ, Murphy KM, Chaplin DD. Modulation of airway inflammation by passive transfer of allergen-specific Th1 and Th2 cells in a mouse model of asthma. J Immunol 1999; 162: 2375-2383.

31 Li L, Xia Y, Nguyen A, Feng L, Lo D. Th2-induced eotaxin expression and eosinophilia coexist with Th1 responses at the effector stage of lung inflammation. J Immunol 1998; 161: 3128-3135.

32 Fleming CM, He H, Ciota A, Perkins D, Finn PW. Administration of pentoxifylline during allergen sensitization dissociates pulmonary allergic inflammation from airway hyperresponsiveness. J Immunol 2001; 167: 1703-1711.

33 Koch M, Witzenrath M, Reuter C, et al. Role of local pulmonary IFN- $\gamma$ expression in murine allergic airway inflammation. Am J Respir Cell Mol Biol 2006; 35: 211-219.

34 Bates J, Irvin C, Brusasco V, et al. The use and misuse of Penh in animal models of lung disease. Am J Respir Cell Mol Biol 2004; 31: 373-374.

35 Adler A, Cieslewicz G, Irvin CG. Unrestrained plethysmography is an unreliable measure of airway responsiveness in BALB/c and C57BL/6 mice. J Appl Physiol 2004; 97: 286-292. 